\title{
Patient preferences and willingness to pay for innovations in intermittent self-catheters
}

\author{
This article was published in the following Dove Press journal: \\ Patient Preference and Adherence \\ 9 March 2015 \\ Number of times this article has been viewed
}

\author{
Binny Pinder' \\ Andrew J Lloyd' \\ Beenish Nafees' \\ Eric P Elkin ${ }^{2}$ \\ Jerome Marley ${ }^{3}$ \\ 'ICON plc, Oxford, UK; ${ }^{2} \mathrm{ICON}$ plc, \\ San Francisco, CA, USA; ${ }^{3}$ School \\ of Nursing, University of Ulster, \\ Newtownabbey, UK
}

Correspondence: Beenish Nafees ICON plc, Seacourt Tower, West Way, Oxford OX2 0JJ, UK

Tel +447957634 I70

Email beenish.nafees@iconplc.com
Background: Intermittent catheterization is the gold standard for bladder management in Europe in people with spinal cord injuries. The aim of the present study was to identify and investigate individuals' preferences regarding intermittent self-catheterization (ISC) devices and furthermore investigate the willingness to pay for attributes in ISC devices in the UK, France, and the Netherlands.

Methods: A discrete choice experiment survey was conducted to evaluate the patients' perceived value of catheter features. Attributes were selected based upon a literature review of the most important characteristics of catheters and the survey was developed and validated with input from patients and medical experts. Data were analyzed using the conditional logit model whereby the coefficients obtained from the model provided an estimate of the (log) odds ratios of preference for attributes. Willingness to pay was estimated for all levels of the attributes.

Results: Two-hundred and eighty-three participants completed the questionnaire and were included in data analysis. Risk of infection had the highest odds ratios as preferred important attribute for all three countries followed by ease of insertion. "Pre-coated catheters" was found to be valued as the most preferred coating technology across all countries. Out of pocket cost was a significant influence on patients' choice.

Conclusion: Users of ISC perceive the value of convenience (size of catheter), ease of insertion, and reduced risk of infection as the most important features attached to an intermittent catheter. These results are applicable both for the "classic" ISC user as well as for another broad group of catheter dependent individuals.

Keywords: self-intermittent catheterization, utility, discrete choice experiment, perceived value

\section{Introduction}

Neurogenic lower urinary tract dysfunction is a dysfunction of the urinary bladder and usually causes difficulty or full inability to empty the bladder without using a catheter. It is often associated with spinal cord diseases and neural tube defects including spina bifida, but also other diseases with neurological damage such as multiple sclerosis are often associated with aneurogenic lower urinary tract dysfunction. Intermittent catheterization has been identified as the gold standard treatment option for individuals with neurogenic lower urinary tract dysfunction ${ }^{1,2}$ compared with other types of catheterization such as indwelling catheters, because of numerous health benefits including a lower risk of developing urinary tract infections (UTIs), pyelonephritis, and renal inflammation. ${ }^{3-6}$ Intermittent self-catheterization (ISC) is intended to be performed by the person him/ herself but where necessary, ISC can be performed by close relatives or caregivers as well as health professionals. ISC has a great impact for the user's psychological and social well-being with higher freedom to decide when and where to perform the procedure. The user's need for privacy and discretion to avoid embarrassment ${ }^{7,8}$ can be supported by more discreet, instant ready-to-use and compact catheters..$^{9,10}$ Health-related quality 
of life (HRQL) has also been demonstrated to be higher for ISC users using compact catheters compared to standard straight intermittent catheter users. ${ }^{11}$ However, other features of a catheter may be of high importance for the users as well, where relatively small improvements in functionality or performance can lead to significant improvements in HRQL. Nevertheless, it is impossible to assess the cost effectiveness of specific improvements in catheter design by generic HRQL measures such as the EuroQol-5D questionnaire (EQ-5D) or the Short form (36) Health survey (SF-36).

An alternative mechanism of capturing these benefits is through the assessment of willingness to pay (WTP), eg, the amount a user is willing to pay for specific new features and technology in catheter design. A way to assess the WTP is by undertaking a discrete choice experiment (DCE) - a stated preference survey method. DCEs have been increasingly utilized to help understand preferences in the field of health and health care. ${ }^{12-15}$ DCEs identify key characteristics of a product (referred to as "attributes") with varying levels associated with each attribute. Attribute levels can be bundled together as a profile (to reflect a specific treatment or product). Participants are presented with a sequence of hypothetical treatment scenarios (choice sets) that vary in terms of the levels of each of the attributes and participants are asked to indicate which option they prefer. From this, the importance of each attribute to the participant and the trade-offs between attributes can be estimated using regression analysis.

The aim of the present study was to identify and investigate individuals' perceived value regarding intermittent catheter and furthermore investigate the WTP for attributes in intermittent catheter in UK, France, and the Netherlands.

\section{Materials and methods Identification of attributes}

A literature review based on an existing study on ISC $^{16}$ was undertaken to determine intermittent catheter characteristics, considered important by individuals relying on ISC. The review was conducted to inform a patient survey and therefore considered relevant in this study. The findings of the review were discussed by the study team and five attributes were selected for inclusion in the DCE. These five attributes were identified based on findings from a previous study ${ }^{17}$ and by reviewing product characteristics of different catheters that are currently available. The attributes included "convenience" (relating to catheter size), "catheter coating" (relating to lubrication and ease of use), "ease of insertion" (relating to ability to use the catheter), "risk of infection" (relating to risk of UTI or UTI associated with catheter use) and "out of pocket cost", which reflects how much participants would be willing to pay on a monthly basis for the device).

Each of the five attributes had three levels ranked in a sequential order. For the survey questionnaire, a separation of male and female version existed with sex specific measurements of the catheter size (Table 1).

\section{Development of DCE survey}

The attributes and levels were combined into choice sets using a published orthogonal array. ${ }^{18}$ An orthogonal fractional factorial design was used to identify the minimum specification of the DCE experimental design in order to fairly represent combinations of the attributes and levels. These combinations were paired using a fold-over design. Each choice question presented two hypothetical intermittent catheters (catheter A or catheter B) and participants were asked to indicate which they preferred (Table 1). The survey included 19 pairs of choice sets, 18 as dictated by the statistical design plus an additional choice to permit an assessment of consistency. The consistency check involved one choice question being repeated and reversed so that what was choice A became choice B. In addition, participants were asked to state whether they would choose their selected hypothetical intermittent catheter over their current intermittent catheter. Background information regarding socio-demographics, experience of current intermittent catheter, medical history, and HRQL (assessed using EQ-5D, a standardized instrument used as a measure of health outcomes/status), was collected. Participants additionally completed the the Intermittent SelfCatheterization Questionnaire (ISC-Q), which captured their views regarding their current device in terms of ease of use, convenience, discreetness, and psychological well-being. ${ }^{16}$

An electronic version of the DCE survey in a format appropriate for administration via the web was developed. This was designed to be easy to use as much as possible, eg, issues of ease of navigation online, moving back and forth in the survey, and comprehensiveness. The survey was translated into French and Dutch using a forward-back translation approach.

\section{Patient interviews}

Telephone-based interviews were conducted to explore participants' understanding of the survey questions with individuals using ISC in the UK $(n=3)$, France $(n=2)$, and the Netherlands $(n=2)$. Participants were asked to complete the survey and then complete a cognitive debrief exercise in which they would comment on how accurate and appropriate the survey was. Participants were asked to comment on the clarity of the questions, the response options, and ease 
Table I Attributes and levels included in the DCE

\begin{tabular}{|c|c|}
\hline Attribute & Level \\
\hline \multirow[t]{3}{*}{ Convenience } & - The catheter is small and compact (male $19 \mathrm{~cm}$; female $9 \mathrm{~cm}$ ) \\
\hline & - The catheter is moderately sized (male device $47 \mathrm{~cm}$; female $19 \mathrm{~cm}$ ) \\
\hline & - The catheter is not compact and can be bulky (male device $57 \mathrm{~cm}$; female $27 \mathrm{~cm}$ ) \\
\hline \multirow[t]{3}{*}{ Catheter coating } & - The catheter is pre-coated with lubricant and needs no preparation \\
\hline & - Add water to the packaging for approximately 30 seconds to lubricate it \\
\hline & - Apply gel to the catheter to lubricate it \\
\hline \multirow[t]{4}{*}{ Risk of infection } & In the next 12 months you will have: \\
\hline & - No urinary tract infections \\
\hline & - You will have one urinary tract infection \\
\hline & - You will have three urinary tract infections \\
\hline \multirow[t]{3}{*}{ Ease of insertion } & - Easy to insert the catheter \\
\hline & - Moderately easy to insert the catheter \\
\hline & - Difficult to insert the catheter \\
\hline \multirow[t]{3}{*}{ Willingness to pay } & - $€ 24$ (UK), ${ }^{a} € 30$ (France), $€ 30$ (the Netherlands) \\
\hline & - $€ 47$ (UK), ${ }^{a} € 60$ (France), $€ 55$ (the Netherlands) \\
\hline & - €7I (UK), $€ 90$ (France), €85 (the Netherlands) \\
\hline
\end{tabular}

Note: ${ }^{a} U K$ pounds were converted to Euros using an exchange rate of I.I8 as of April 3, 2013.

Abbreviation: DCE, discrete choice experiment.

of completion of the overall survey. A study panel was used for participant recruitment and included participants who had experience with ISC. All provided informed consent, and this DCE study was granted ethical approval by an independent review board (Salus Institutional Review Board OXO-0649-0006) in the US. Cultural acceptability was specifically assessed in the French and Dutch interviews.

Participants reported that the survey was easy to understand and complete. Payment for catheters was queried as standard intermittent catheters are fully reimbursed in the three countries. Therefore, the following phrase was inserted in the survey: "We are still interested in how much you would be willing to pay for your catheter regardless of whether you currently pay or not".

\section{Expert interviews}

Semi-structured telephone interviews with two experts in the field of catheters (a urologist and a specialist nurse) were undertaken. The experts reviewed the DCE survey and provided input on its suitability and clinical relevance. Minor revisions were made, including the inclusion of the following phrase, "Please note: If you pay nothing for your catheters, there are no plans to change this". All appropriate revisions to the DCE survey were implemented (final attributes presented in Table 1).

\section{Main study}

The Salus Institutional Review Board (ref OXO-0649-0006) approved the study protocol and all case-report forms, including the final DCE survey.

\section{Sample}

Participants were recruited through a panel of catheter users in the UK, France, and the Netherlands. Inclusion criteria were i) at least 12 months post-injury, ii) used ISC as their main method of bladder management, iii) did not frequently use a catheter set, iv) had used ISC for at least 6 months, v) were aged between 18 and 85 years, vi) had access to the internet, and vii) were currently a resident in the UK, France or the Netherlands. Exclusion criterion was i) an acute illness or cognitive impairment that in the opinion of the interviewer would interfere with the study requirements. All potential participants were required to provide online consent before they had access to the DCE survey. Participants received a small compensation at the completion of the survey.

\section{Data analysis}

Socio-demographic and medical information were analyzed as means, standard deviations, and frequencies or percentages. The EQ-5D was scored using standard UK preference weights, ${ }^{19}$ whereby full health has a value of 1.0 and dead has a value of 0 .

The choice data were analyzed using a conditional logit model to explore the impact of each attribute on participants' choices. The conditional logit model evaluates choice responses after conditioning them on the attributes of the other alternatives available within the choice set. Hence, if, for example, "catheter option A" is preferred in the choice set 1 , this preference is conditional on the attributes of "catheter option B". The coefficients obtained from the logit 
model provide an estimate of the (log) odds ratios (ORs) of preference for catheter attributes. To see if any countryspecific difference in the preferences of attributes would appear, interaction terms were also included in a subsequent analysis. Within each attribute one level was set as reference point against other levels (Table 2). A profile of different hypothetical catheters was estimated based on each attribute. The profiles showed the likelihood of choosing a catheter and WTP over the base case (can be bulky, apply gel to lubricate, three infections in 12 months, difficult to insert). WTP was calculated by dividing the estimated coefficients for each attribute by the coefficient for out of pocket cost (so called marginal rates of substitution).

\section{Results}

\section{Participant characteristics}

Three-hundred and sixteen participants completed the study questionnaires. Thirty-three participants were excluded due to failure on the consistency check, resulting in 283 participants $(\mathrm{N}=140$ in $\mathrm{UK}, \mathrm{N}=90$ in France, $\mathrm{N}=53$ in the Netherlands).

The mean age of the total sample was 51 years with majority being male (55\% in UK, 70\% in France, and 81\% in the Netherlands). Table 3 presents the clinical history of participants in each country. The French sample reported a longer history of using ISC (14 years) than UK and the Netherlands (UK $=8$ years and the Netherlands $=10$ years). Fifty-two percent of the participants reported to be wheelchair users mainly in France and the Netherlands, as the UK population had $26 \%$ using a wheelchair. The mean EQ-5D index score for participants at survey was 0.56 for UK, 0.48 for France, and 0.40 for the Netherlands, reflecting these differences. For the French and Dutch groups, the majority of respondents had paraplegia and were wheelchair users. The UK group was a bit different as the use of ISC was caused by having multiple sclerosis and other illnesses, with the majority of the British sample reporting that they were walking/walking with difficulties.

The majority of participants reported that their current catheter was easy to use, easy to insert, and that storage of their catheter at home was inconvenient. However, a variety of responses appeared regarding discreetness of the catheter and the impact the current catheter has on the psychological well-being. Participants were to state which level best described their current catheter (Table 4), where most had either a "small and compact" or "moderately sized" catheter. Concerning preparation, the majority had a catheter that was instantly ready-to-use without additional equipment or waiting time (79\% in UK, $86 \%$ in France, and $87 \%$ in the Netherlands).

\section{DCE findings}

In the UK sample, all attributes were significant predictors of choice (Table 2 ). The most highly valued attributes included risk of infection $(\mathrm{OR}=4.00)$ and ease of insertion $(\mathrm{OR}=2.53)$. The OR means that all other things equal, participants in the survey were four times more likely to prefer a device which was associated with no infections compared to one that was

Table 2 Results of conditional logit model, including odds ratios for preference of attribute levels for all countries

\begin{tabular}{|c|c|c|c|c|c|c|c|c|c|c|}
\hline \multirow[t]{2}{*}{ Parameter } & \multirow[t]{2}{*}{ Level $^{\mathrm{a}}$} & \multicolumn{3}{|l|}{ UK } & \multicolumn{3}{|c|}{ France } & \multicolumn{3}{|c|}{ the Netherlands } \\
\hline & & OR & $95 \% \mathrm{Cl}$ & WTP (€) & OR & $95 \% \mathrm{Cl}$ & WTP (€) & OR & $95 \% \mathrm{Cl}$ & WTP (€) \\
\hline \multirow[t]{3}{*}{ Convenience } & Small and compact & 2.364 & $2.047-2.730$ & 59.69 & 1.553 & I.309-|.84| & 48.89 & 2.173 & I.709-2.763 & 86.22 \\
\hline & Moderately sized & $\mathrm{I} .874$ & $1.622-2.166$ & 43.59 & $\mathrm{I} .454$ & I.223-I.729 & 41.67 & 1.913 & $1.496-2.446$ & 72.11 \\
\hline & Can be bulky (reference) & NA & NA & NA & NA & NA & NA & NA & NA & NA \\
\hline Catheter & Pre-coated with lubricant & 1.939 & $|.677-2.24|$ & 45.95 & 1.808 & $1.518-2.155$ & 65.78 & 2.041 & $1.591-2.620$ & 79.33 \\
\hline \multirow[t]{2}{*}{ coating } & $\begin{array}{l}\text { Add water for } 30 \text { seconds } \\
\text { to lubricate }\end{array}$ & 1.213 & $1.061-1.386$ & 13.39 & 1.166 & $0.991-1.373$ & |7.|I & I. $145^{b}$ & $0.916-1.431$ & 15.00 \\
\hline & $\begin{array}{l}\text { Apply gel to lubricate } \\
\text { (reference) }\end{array}$ & NA & NA & NA & NA & NA & NA & NA & NA & NA \\
\hline Risk of & No infections in 12 months & 4.004 & $3.444-4.654$ & 96.28 & 3.275 & $2.740-3.914$ & $|3| .78$ & $5.57 \mid$ & $4.295-7.225$ & 190.78 \\
\hline \multirow[t]{2}{*}{ infection } & One infection in 12 months & 2.549 & $2.215-2.933$ & 64.97 & 2.076 & $1.760-2.449$ & 81.11 & 2.820 & $2.238-3.553$ & I 15.22 \\
\hline & $\begin{array}{l}\text { Three infections in } 12 \text { months } \\
\text { (reference) }\end{array}$ & NA & NA & NA & NA & NA & NA & NA & NA & NA \\
\hline Ease of & Easy & 2.533 & $2.191-2.929$ & 64.49 & 3.053 & $2.56 I-3.640$ & 124.00 & 2.298 & $1.809-2.919$ & 92.44 \\
\hline \multirow[t]{2}{*}{ insertion } & Moderately easy & 1.943 & $|.692-2.23|$ & 46.11 & 2.368 & $2.00 \mathrm{I}-2.802$ & 95.78 & $\mathrm{I} .808$ & $1.425-2.294$ & 65.78 \\
\hline & Difficult (reference) & NA & NA & NA & NA & NA & NA & NA & NA & NA \\
\hline Cost & Per $€ I 0$ decrease & 1.187 & $|| 45-1.23 \mid$. & NA & 1.090 & $1.059-1.121$ & NA & 1.100 & I.053-I.I49 & NA \\
\hline
\end{tabular}

Notes: ${ }^{a}$ The worst level of each attribute is the reference case. ${ }^{b}$ Not significant at $P<0.01$.

Abbreviations: OR, odds ratio; $\mathrm{Cl}$, confidence interval; NA, not applicable; WTP, willingness to pay. 
Table 3 Clinical history of participants

\begin{tabular}{|c|c|c|c|c|c|}
\hline Parameter & Sub category & Total $(n=283)$ & UK $(n=\mid 40)$ & France $(n=90)$ & $\begin{array}{l}\text { the Netherlands } \\
(n=53)\end{array}$ \\
\hline Age, n (\%) & NA & $51.01(13.25 \%)$ & $53.14(13.96 \%)$ & 49.5 (I2.26\%) & 47.94 (12.18\%) \\
\hline Sex (female) & NA & $100(35 \%)$ & $63(45 \%)$ & 27 (30\%) & $10(19 \%)$ \\
\hline $\begin{array}{l}\text { Duration of use of } \\
\text { intermittent self-catheters } \\
\text { (years), mean (SD) }\end{array}$ & NA & $10.42(7.32)$ & $8.28(6.66)$ & $13.93(7.50)$ & $10.11(6.45)$ \\
\hline Position that intermittent & In my wheelchair & 105 (37\%) & $24(17 \%)$ & $54(60 \%)$ & 27 (5I\%) \\
\hline self-catheter is most & On the toilet & $98(35 \%)$ & $60(43 \%)$ & $25(28 \%)$ & $13(25 \%)$ \\
\hline \multirow[t]{3}{*}{ frequently used, n (\%) } & On my bed & $14(5 \%)$ & $3(2 \%)$ & $5(5 \%)$ & $6(11 \%)$ \\
\hline & I stand up & $62(22 \%)$ & 49 (35\%) & $6(6 \%)$ & $7(13 \%)$ \\
\hline & Other & $4(1 \%)$ & $4(3 \%)$ & $0(0 \%)$ & $0(0 \%)$ \\
\hline Most frequently used & NA & $78(28 \%)$ & $13(9 \%)$ & $45(50 \%)$ & $33(62 \%)$ \\
\hline urine bag, n (\%) & & $205(72 \%)$ & 127 (9|\%) & $45(50 \%)$ & $20(38 \%)$ \\
\hline Classification of injury/ & Complete paraplegia & $86(30 \%)$ & 12 (9\%) & 42 (47\%) & $32(60 \%)$ \\
\hline \multirow[t]{5}{*}{ condition, n (\%) } & Incomplete paraplegia & $78(28 \%)$ & $29(21 \%)$ & $30(32 \%)$ & $19(36 \%)$ \\
\hline & Complete tetraplegia & $4(1 \%)$ & I (I\%) & $3(4 \%)$ & $0(0 \%)$ \\
\hline & Incomplete tetraplegia & $20(7 \%)$ & $5(4 \%)$ & $13(15 \%)$ & $2(4 \%)$ \\
\hline & Not sure & $26(9 \%)$ & $25(18 \%)$ & I (I\%) & $0(0 \%)$ \\
\hline & Not applicable & $69(24 \%)$ & $68(47 \%)$ & I (I\%) & $0(0 \%)$ \\
\hline Cause of injury/condition, & Road traffic accident & $67(23 \%)$ & $16(11 \%)$ & 33 (37\%) & $18(33 \%)$ \\
\hline \multirow[t]{12}{*}{ n (\%) } & Sports related accident & $24(9 \%)$ & $4(3 \%)$ & $12(13 \%)$ & $8(15 \%)$ \\
\hline & Work related accident & $21(7 \%)$ & $7(5 \%)$ & $10(11 \%)$ & $4(8 \%)$ \\
\hline & Fall & $32(11 \%)$ & $14(10 \%)$ & $9(10 \%)$ & $9(17 \%)$ \\
\hline & Tumor on the spine & $10(4 \%)$ & $4(3 \%)$ & $5(6 \%)$ & I $(2 \%)$ \\
\hline & Spina Bifida & $7(3 \%)$ & $4(3 \%)$ & $2(2 \%)$ & I (2\%) \\
\hline & Multiple Sclerosis & $22(8 \%)$ & $21(15 \%)$ & $\mathrm{I}(\mathrm{I} \%)$ & $0(0 \%)$ \\
\hline & Motor Neuron Disease & $0(0 \%)$ & $0(0 \%)$ & $0(0 \%)$ & $0(0 \%)$ \\
\hline & Arthritis & $\mathrm{I}(0.3 \%)$ & $\mathrm{I}(\mathrm{I} \%)$ & $0(0 \%)$ & $0(0 \%)$ \\
\hline & Other: & & & & \\
\hline & Medical complications & $13(5 \%)$ & $7(5 \%)$ & $3(3 \%)$ & $3(6 \%)$ \\
\hline & $\begin{array}{l}\text { Other illness (Transverse myelitis, } \\
\text { pelvic floor dysfunction, degenerative } \\
\text { disc, Fowlers Syndrome and others) }\end{array}$ & $72(25 \%)$ & $49(35 \%)$ & $15(17 \%)$ & $8(15 \%)$ \\
\hline & Unknown & II (4\%) & II (8\%) & $0(0 \%)$ & $0(0 \%)$ \\
\hline \multirow[t]{4}{*}{ Mobility status, n (\%) } & Walking & $56(20 \%)$ & $53(38 \%)$ & $0(0 \%)$ & $3(6 \%)$ \\
\hline & Walking with difficulty/aids & $74(26 \%)$ & $49(35 \%)$ & $20(22 \%)$ & $5(9 \%)$ \\
\hline & Using a wheelchair & | 48 (52\%) & $37(26 \%)$ & 67 (74\%) & $44(83 \%)$ \\
\hline & Confined to bed or a chair & $5(2 \%)$ & I (I\%) & $3(3 \%)$ & I (2\%) \\
\hline EQ-5D index score, mean (SD) & NA & $0.50(0.35)$ & $0.56(0.34)$ & $0.48(0.33)$ & $0.40(0.36)$ \\
\hline
\end{tabular}

Abbreviations: NA, not applicable; SD, standard deviation; EQ-5D, EuroQol-5D questionnaire.

likely to cause three infections in the next 12 months. To avoid all infections, participants were willing to pay $€ 96.28$ a month. Participants were almost twice as likely to prefer a device which was "pre-coated with lubricant" $(\mathrm{OR}=1.94)$. Notwithstanding these clinical benefits, participants were over twice as likely $(\mathrm{OR}=2.36)$ to prefer a small and compact device compared with one considered bulky. Participants were willing to pay $€ 59.59$ a month for a small and compact catheter over and above any clinical benefits. Cost was a significant negative predictor of choice in all three countries.

In the French sample, all attributes were significant predictors of choice, except one level of "catheter coating" ("add water for 30 seconds to lubricate"). The highest ORs were for risk of infection ( $\mathrm{OR}=3.28)$, ease of insertion $(\mathrm{OR}=3.05)$, and pre-coated catheter $(\mathrm{OR}=1.81)$. French participants were willing to pay $€ 131.78$ a month to avoid all infections and were even willing to pay $€ 81.11$ a month extra if they only experience one infection in the next 12 months. Participants preferred catheters which were "small and compact" $(\mathrm{OR}=1.55)$ or "moderately sized" $(\mathrm{OR}=1.45)$. The levels for ease of insertion are slightly more important for the French sample which perhaps reflects their greater level of disability. Participants were willing to pay $€ 124$ a month for a device which is easy to insert. Similar to the UK, 
Table 4 Participants' experience of current catheter

\begin{tabular}{|c|c|c|c|c|}
\hline & Total $(n=283)$ & UK $(n=\mid 40)$ & France $(n=90)$ & the Netherlands $(n=53)$ \\
\hline \multicolumn{5}{|l|}{ Convenience, n (\%) } \\
\hline Small and compact & III (39\%) & $64(46 \%)$ & $25(28 \%)$ & $22(42 \%)$ \\
\hline Moderately sized & $128(45 \%)$ & $56(40 \%)$ & $48(53 \%)$ & $24(45 \%)$ \\
\hline Not compact and bulky & $31(11 \%)$ & $15(11 \%)$ & $10(11 \%)$ & $6(11 \%)$ \\
\hline Missing & $13(5 \%)$ & $5(4 \%)$ & $7(8 \%)$ & I (2\%) \\
\hline \multicolumn{5}{|l|}{ Catheter coating, n (\%) } \\
\hline Requires no preparation before use & $234(83 \%)$ & III (79\%) & $77(86 \%)$ & $46(87 \%)$ \\
\hline Need to add water for 30 seconds to lubricate & $46(16 \%)$ & $26(19 \%)$ & $13(14 \%)$ & $7(13 \%)$ \\
\hline Need to apply gel to lubricate & $\mathrm{I}(0 \%)$ & $\mathrm{I}(\mathrm{I} \%)$ & $0(0 \%)$ & $0(0 \%)$ \\
\hline Missing & $2(1 \%)$ & $2(1 \%)$ & $0(0 \%)$ & $0(0 \%)$ \\
\hline \multicolumn{5}{|l|}{ Infection in the last 12 months, $\mathrm{n}(\%)$} \\
\hline Yes & 166 (59\%) & $78(56 \%)$ & $63(70 \%)$ & $25(47 \%)$ \\
\hline No & $117(4 \mid \%)$ & $62(44 \%)$ & $27(30 \%)$ & $28(53 \%)$ \\
\hline \multicolumn{5}{|l|}{ Number of infections in the last 12 months ${ }^{a}$} \\
\hline$N$ & 166 & 78 & 63 & 25 \\
\hline Mean (SD) & $3.40(3.44)$ & $3.73(3.38)$ & $3.33(3.92)$ & $2.56(2.02)$ \\
\hline \multicolumn{5}{|l|}{ Ease of insertion, $\mathbf{n}(\%)$} \\
\hline Easy to insert & $211(75 \%)$ & $96(69 \%)$ & $70(78 \%)$ & 45 (85\%) \\
\hline Moderately easy to insert & $64(23 \%)$ & $42(30 \%)$ & $14(16 \%)$ & $8(15 \%)$ \\
\hline Difficult to insert & $3(1 \%)$ & $\mathrm{I}(\mathrm{I} \%)$ & $2(2 \%)$ & $0(0 \%)$ \\
\hline Missing & $5(2 \%)$ & $\mathrm{I}(\mathrm{I} \%)$ & $4(4 \%)$ & $0(0 \%)$ \\
\hline \multicolumn{5}{|c|}{ Do you currently pay for your catheters? ${ }^{\mathrm{a}, \mathrm{b}} \mathbf{n}(\%)$} \\
\hline Currently pay nothing & $269(95 \%)$ & 127 (9|\%) & $90(100 \%)$ & $52(98 \%)$ \\
\hline Currently pay something for my catheters & $14(5 \%)$ & $13(9 \%)$ & $0(0 \%)$ & I (2\%) \\
\hline
\end{tabular}

Notes: ${ }^{a}$ Among patients who had urinary tract infection. ${ }^{b}$ Among patients who are paying for their catheters.

Abbreviation: SD, standard deviation.

cost was a significant consideration in choosing a catheter as listed in Table 2.

All attributes were significant predictors of choice for the Netherlands sample, but there were some interesting differences to the UK and French participants. Avoiding any risk of infection was the most important attribute ( $\mathrm{OR}=5.57$ or $€ 190.78)$. Small and compact or moderately size catheters were preferred (OR=2.17, OR=1.91 respectively or $€ 86$ and $€ 72$ respectively). Pre-coated catheters with lubricant $(\mathrm{OR}=2.04)$ that were easy to insert were also preferred $(\mathrm{OR}=2.30)$.

An analysis of the full model with interaction terms for country identified that the Dutch sample placed significantly more value on avoiding infections than the UK sample. Also, the UK sample had a stronger preference to avoid bulky catheters than the French sample, which were less concerned by this. These results were not statistically significantly different.

The French and Dutch samples were using a moderately sized catheter at the time while the UK sample was using small and compact intermittent catheters. The majority of respondents reported using a catheter which did not require any preparation before use in relation to lubrication thus increasing ease of use. Most individuals in the sample had experienced a UTI within the last year with an average episode 3.4 UTIs.

\section{Discussion}

The current study investigated the use of and perceived value for intermittent catheters through the use of a DCE experiment. Two-hundred and eighty-three participants from UK, France, and the Netherlands with a history of using ISC completed the survey. The survey explored users' perception of convenience in relation to the size, catheter coating technology, risk of infection per year, ease of insertion, and out-of-pocket cost. This is the first study investigating the user's perceived value of intermittent catheter design.

The participants' clinical history revealed that participants had been using ISC for 10 years, with most having complete or incomplete paraplegia in the French (74\%) and Dutch (96\%) sample. The UK sample differed considerably in etiology and level of functioning as their main reason for using ISC was caused by multiple sclerosis or other illness (50\%) and only $30 \%$ had complete or incomplete paraplegia. For the same reason, only $26 \%$ of the UK participants were wheelchair users. For participants from France and the Netherlands, ISC was caused by traffic, sport or work related accidents, and most were wheelchair users (74\% and 83\% respectively). Taken together, this broad group of users illustrates that results are applicable both for the classic ISC 
users, but also for other groups such as individuals who had multiple sclerosis or other medical conditions.

All attributes were significant predictors of choice except one level of catheter coating in France and the Netherlands. This demonstrates that participants found that all attributes were relevant when considering a new catheter. The three most important attributes for participants in all countries were the "size of catheter", "risk of infection", and "ease of insertion".

All participants rated a small and compact catheter as the most preferred, a catheter that currently was used by $46 \%$ in the UK, 28\% in France, and 42\% in the Netherlands. This preference is in compliance with a newly published study by Chartier-Kastler et $\mathrm{al}^{11}$ that demonstrated a $28 \%$ improvement in catheter-related quality of life for those using a compact catheter compared to a standard sized catheter. These two studies combined indicate that a vast majority of the participants in these three countries use a moderate or bulky catheter, which is not their most preferred catheter size. The findings are important as they highlight a level of unmet need among users in the specific countries.

In this study, the risk of UTI was the largest reported concern and consequently, the most preferred attribute was how to avoid an infection. Following UTIs, the ease of insertion was an important attribute, which is a common issue associated with the use of ISCs. ${ }^{20}$ Improvement in ease of use can entail many benefits in users' catheterization such as: less pain in muscles or urethra and improvement in control during the insertion process, with potential long-term urinary tract health. ${ }^{8}$ The results revealed that ease of insertion has significant importance of the attributes for catheter users following the risk of infection. The French sample indicated a significantly higher perceived value for this attribute than the British or Dutch sample, which might be caused by the higher percentage of participants performing ISC from a wheelchair.

Participants reported pre-coated catheters as the preferred coating technology in all countries. The British sample additionally valued the "add water" component as more preferable than the gel, but less important than the pre-coated catheter. Giannantoni et al reported in 2001 that the precoated technology of intermittent catheters was associated with an increase in user satisfaction, a finding in line with the present study. ${ }^{17}$

Cost was an important driver of preferences in all countries, which supported our estimation of WTP. The results indicated how important attributes were in terms of WTP and the amounts participants were willing to pay every month for a more advanced catheter technology. These data may be useful information for priority setting around future treatments.
There are some important limitations to this study. The composition of the recruitment panel was a majority of current Coloplast catheter consumers which potentially could result in possible bias in their experience of using catheters. However, participants reported the use of a broad range of catheters in their clinical history. In addition, an online survey was used for data collection, which may have restricted access to the survey for some potential participants. In spite of this, the findings were consistent with previous literature ${ }^{3,20}$ and provide further insight into the value people place on various aspects of catheters.

Lastly the estimation of WTP may be criticized because most of the participants in this study had no experience of paying for their ISCs. If people do not have to buy a product, then their indications of maximum WTP may be biased. It is unclear from this survey if these WTP values really reflect what catheter users would be willing and able to pay. Further work would be needed to establish that. The WTP values in Table 2 can be taken to represent users' strength of preference and the importance that they place on the attributes of ISC devices. What is clear is that ISC users have a demand for innovation in the design of intermittent catheters and do recognize the value of improvements in technology design.

\section{Conclusion}

This study identified catheter users' perceived value for different aspects of ISC in the UK, France, and the Netherlands. Convenience, ease of insertion, and risk of infection are the most important attributes of ISC for catheter users. The results are similar both for "classic" ISC users (with complete/incomplete paraplegia, wheelchair users, etc) but also for another broad group of ISC users (eg, multiple sclerosis patients, spina bifida patients, etc). The DCE method allows clinicians and decision makers to identify important features of catheters that are essential to users and contribute to the understanding of preference, satisfaction and hence long-term compliance of bladder management method.

\section{Acknowledgments}

This study was supported by research funding from Coloplast A/S to Oxford Outcomes Ltd. No restrictions were, however, placed on the design of the study, the choice of included data sources or the presentation of results. We would specifically like to thank Dr Pierre Denys for expert advice during the construction of the questionnaire. Mia Buus Andersen, Pernille-Julia Vig Hjarnaa and Zenia M Størling contributed with data interpretation and critical scientific review of the manuscript. 


\section{Author contributions}

All authors participated in the design of the study, contributed to and analyzed the data, and drafted and revised the manuscript. They also agree to be accountable for the work.

\section{Disclosure}

The authors report no conflicts of interest in this work.

\section{References}

1. Consortium for Spinal Cord Medicine. Bladder management for adults with spinal cord injury: a clinical practice guideline for health care providers. Washington: Paralyzed Veterans of America; 2006.

2. Stöhrer M, Blok B, Castro-Diaz D, et al. EAU Guidelines on neurogenic lower urinary tract Dysfunction. Eur Urol. 2009;56(1):81-88.

3. Blaine $\mathrm{C}$, Pellowe $\mathrm{C}$, Hodgkinson S. Improving infection prevention practice in primary and community care. J Hosp Infect. 2012; 82(4):274-276.

4. Turi MH, Hanif S, Fasih Q, Shaikh MA. Proportion of complications in patients practicing clean intermittent self-catheterization (CISC) vs. indwelling catheter. J Pak Med Assoc. 2006;56(9):401-404.

5. Warren JW, Muncie HL, Hebel JR, Hall-Craggs M. Long-term urethral catheterization increases risk of chronic pyelonephritis and renal inflammation. J Am Geriatr Soc. 1994;42(12):1286-1290.

6. Niël-Weise BS, van den Broek PJ. Urinary catheter policies for shortterm bladder drainage in adults. Cochrane Database Syst Rev. 2005; (3):CD004203.

7. Shaw C, Logan K, Webber I, Broome L, Samuel S. Effect of clean intermittent self-catheterization on quality of life: A qualitative study. $J$ Adv Nurs. 2008;61(6):641-650.

8. Logan K, Shaw C, Webber I, Samuel S, Broome L. Patients' experiences of learning clean intermittent self-catheterization: a qualitative study. $J$ Adv Nurs. 2008;62(1):32-40.

9. Domurath B, Kutzenberger J, Kurze I, Knoth HS. Clinical evaluation of a newly developed catheter (SpeediCath Compact Male) in men with spinal cord injury: Residual urine and user evaluation. Spinal Cord. 2011;49(7):817-821.
10. Biering-Sørensen F, Hansen HV, Nielsen PN, Looms D. Residual urine after intermittent catheterization in females using two different catheters. Scand J Urol Nephrol. 2007;41(4):341-345.

11. Chartier-Kastler E, Amarenco G, Lindbo L, et al. A prospective, randomized, crossover, multicenter study comparing quality of life using compact vs. standard catheters for intermittent self-catheterization. J Urol. 2013;190(3):942-947.

12. Ryan M. Using discrete choice experiments to value healthcare programmes: Current practice and future research reflections. Appl Health Econ Health Policy. 2003;2(1):55-64.

13. Hall J, Fiebig D, King M, Hossain I, Louviere JJ. What influences participation in genetic carrier testing? Results from a discrete choice experiment. J Health Econ. 2006;25(3):520-537.

14. Scott A, Watson MS, Ross S. Eliciting preferences of the community for out of hours care provided by general practitioners: a stated preference discrete choice experiment. Soc Sci Med. 2003;56(4):803-814.

15. Watson V, Ryan M, Barnett G, Ellis B, Emberton M, Brown C. Eliciting preferences for drug treatment of lower urinary tract symptoms associated with benign prostatic hyperplasia. J Urol. 2004;172(6 Pt 1): 2321-2325.

16. Pinder B, Lloyd AJ, Elwick H, Denys P, Marley J, Bonniaud V. Development and psychometric validation of the intermittent selfcatheterization questionnaire. Clin Ther. 2012;34(12):2302-2313.

17. Giannantoni A, Di Stasi SM, Scivoletto G, Virgili G, Dolci S, Porena M. Intermittent catheterization with a prelubricated catheter in spinal cord injured patients: A prospective randomised crossover study. $J$ Urol. 2001;166(1):130-133.

18. neilsloane.com [homepage on the Internet]. A library of orthogonal arrays. Available from: http://neilsloane.com/oadir/. Accessed March 2, 2013.

19. Dolan P. Modeling valuations for EuroQol health states. Med Care. 1997;35(11):1095-1108.

20. nursingtimes.net [homepage on the Internet]. Yates A. Common problems with intermittent self catheterisation. Available from: http:// www.nursingtimes.net/nursing-practice/clinical-zones/continence/ common-problems-with-intermittent-self-catheterisation/5020300. article. Accessed March 10, 2013.
Patient Preference and Adherence

\section{Publish your work in this journal}

Patient Preference and Adherence is an international, peer-reviewed, open access journal that focuses on the growing importance of patient preference and adherence throughout the therapeutic continuum. Patient satisfaction, acceptability, quality of life, compliance, persistence and their role in developing new therapeutic modalities and compounds to optimize

\section{Dovepress}

clinical outcomes for existing disease states are major areas of interest for the journal. This journal has been accepted for indexing on PubMed Central. The manuscript management system is completely online and includes a very quick and fair peer-review system, which is all easy to use. Visit http://www. dovepress.com/testimonials.php to read real quotes from published authors. 